事訅會本

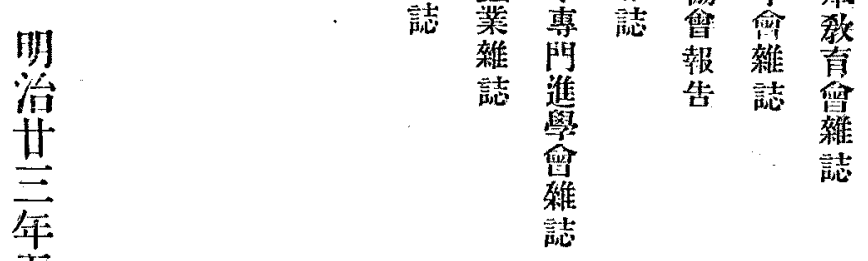

賽 地 日 琵搏 北電大

利學本化蹋水莱目

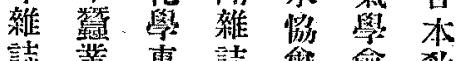

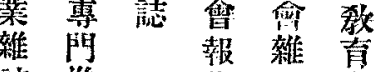

誌進 告 誌 夏

新

誌

第 第 第 第 第 第 第

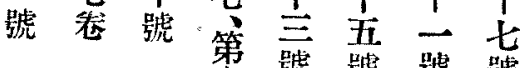

中

心

進

路

)

第號 號 號 號

說

明 號

及

$t$

圖

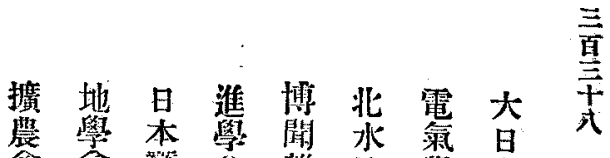

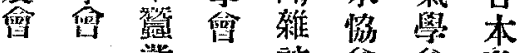

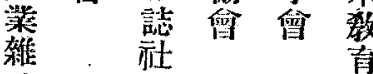

誌曾 


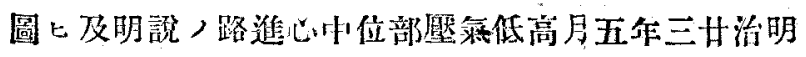

第 管 第 第 籍 第第低 八渄七六。五本四行三失沿三莗一获 乙 行 七十古古十阿西リテ支二支，

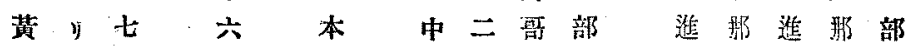
海日海部日斯 3 行東行笨位 ヨ支日,

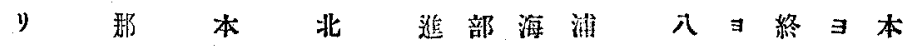
來真海部入 $邓=$ 潮早り

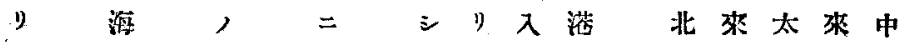

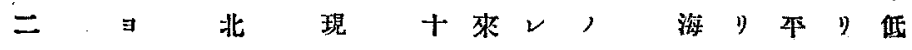
十 y 部 出 三川y南道六淎四州 一 來 $=$ シ 日九部, 日 日9發北南州 $\Rightarrow$ 北九出九， 朝全生海東, 行部州 $\vec{\gamma}$ 州部 鮮 8 道海南逈 $\rightarrow$,, 位

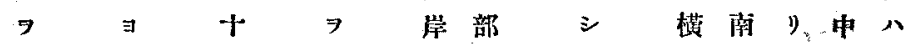
通り七踰,

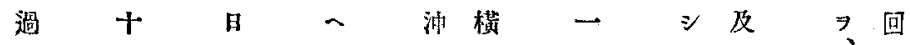
シ 九 北十合逍白, F四五

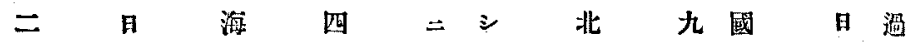
十 =道日於夫海日月四七 二最至最, 最其最テョ最道最二踟最國》

日低 $N$ 低北低東低消》低，低至一低及

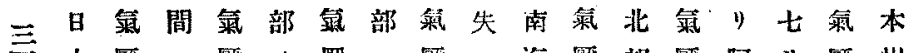

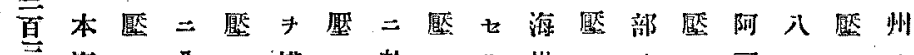
辛海全杪於》岸 $\neq$ 哥, ’

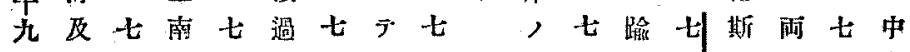
北百海百七百消百中面一百克白百部 海立岸五）五失五部四北四海北五” 道十キ十十七十卉東十二西十横

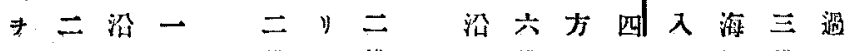

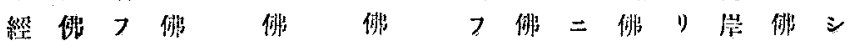

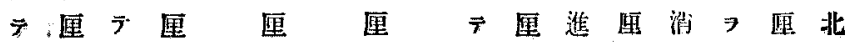


圆七及明境，路進心中位部壓氯低高月五年三甘治明

\begin{tabular}{|c|c|c|c|c|c|c|c|c|c|c|c|c|c|}
\hline \multirow{2}{*}{$\begin{array}{l}\text { 管 } \\
\Xi\end{array}$} & 第 & & 第 & 高 & & 管 & & 第 & & & 第 & 第 & \\
\hline & $=$ & 南 & $\rightarrow$ & 莱 & 婩 & + & 過 & + & $\hat{\imath}$ & 本 & 九 & 八 & \\
\hline & & 東 & & 厴 & 7 & 两 & シ & 乙 & 逐 & 州 & & ๓ & \\
\hline+ & + & 部 & - & , & 沿 & & 北 & & $=$ & , & $=$ & & \\
\hline 四 & - &, & 日 & 部 & 暹 & $\Xi$ & 身 & $\equiv$ & 阿 & 西 & + & $=$ & \\
\hline 日 & II & 沛 & $\exists$ & 位 & t & + & 方 & + & 斯 & 部 & $\boldsymbol{I}$ & + & \\
\hline 朝 & 朝 & 合 & ) & & y & - & $\Rightarrow$ & 日 & 克 & $\Rightarrow$ & 日 & 二 & \\
\hline 鮮 & 鮮 & $\Rightarrow$ & 四 & 本 & & 日 & 駿 & 西 & 酸 & 通 & 级 & 日 & \\
\hline 海 & 海 & 通 & 日 & 月 & & 四 & 行 & 部 & $=$ & 過 & 那 & 本 & \\
\hline 群 & 吙 & 過 & 迲 & 中 & & 國 & $t$ & $\exists$ & 入 & シ & 東 & 洲 & \\
\hline$=$ & $=$ & $t$ & 日 & 高 & & ' & y) & y & 1) & $\#$ & 海 & , & \\
\hline $\boldsymbol{\gamma}$ & 在 & 1) & 本 & 氣 & & 沖 & & 标 & 沙 & t & $\exists$ & 北 & \\
\hline 1) & $y$ & & 海 & 擥 & & 合 & & $y$ & 失 & 日 & 1) & 部 & \\
\hline シ & シ & & $=$ & え & & $=$ & & 朝 & 七 & 日 & 來 & $=$ & \\
\hline カ & $\Rightarrow$ & & 佇 & 部 & & 现 & & 路 & $y$ & 本 & ") & 現 & \\
\hline+ & + & & 留 & 位 & & 出 & & ' & & 海 & 九 & 出 & \\
\hline 五 & $=$ & & $z$ & $\therefore$ & & \# & & 南 & & $\overrightarrow{=}$ & 州 & 七 & \\
\hline 日 & 日 & & צ & 六 & & $\Xi$ & & 部 & & 入 & ; & ע) & \\
\hline$\exists$ & 本 & & y & 回 & & + & & $\Rightarrow$ & & $\mathfrak{y}$ & 南 & & \\
\hline ) & 州 & & シ & 現 & & - & & 經 & & \# & 東 & & \\
\hline+ & $\gamma$ & & 力 & 出 & & 日 & & $\vec{\gamma}$ & & t & 部 & & \\
\hline 入 & 南 & & 五 & 七 & & 及 & & $\equiv$ & & \# & $\Rightarrow$ & & \\
\hline
\end{tabular}

最日最部最日り最六最十最八沿最最 高迄高二高 9 佂月低主低，進低低

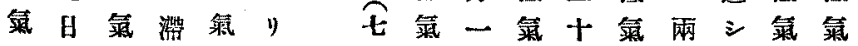

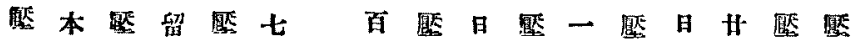

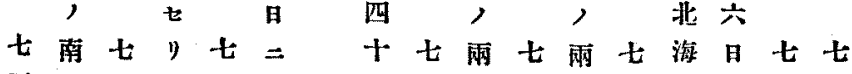
百部面百至百白百百道四百百 六二六兵少佛四南四日五，國五四 十鲩十十問十厘十東十本十西, 十十 三留三八北六八瓜入海三部西三八

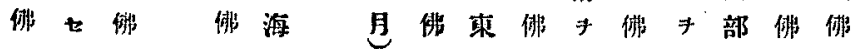

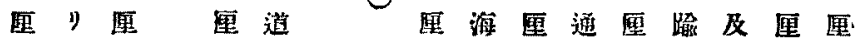




\section{圖七及明說 八路進心中位部壓氮低高月五年三サ治明}

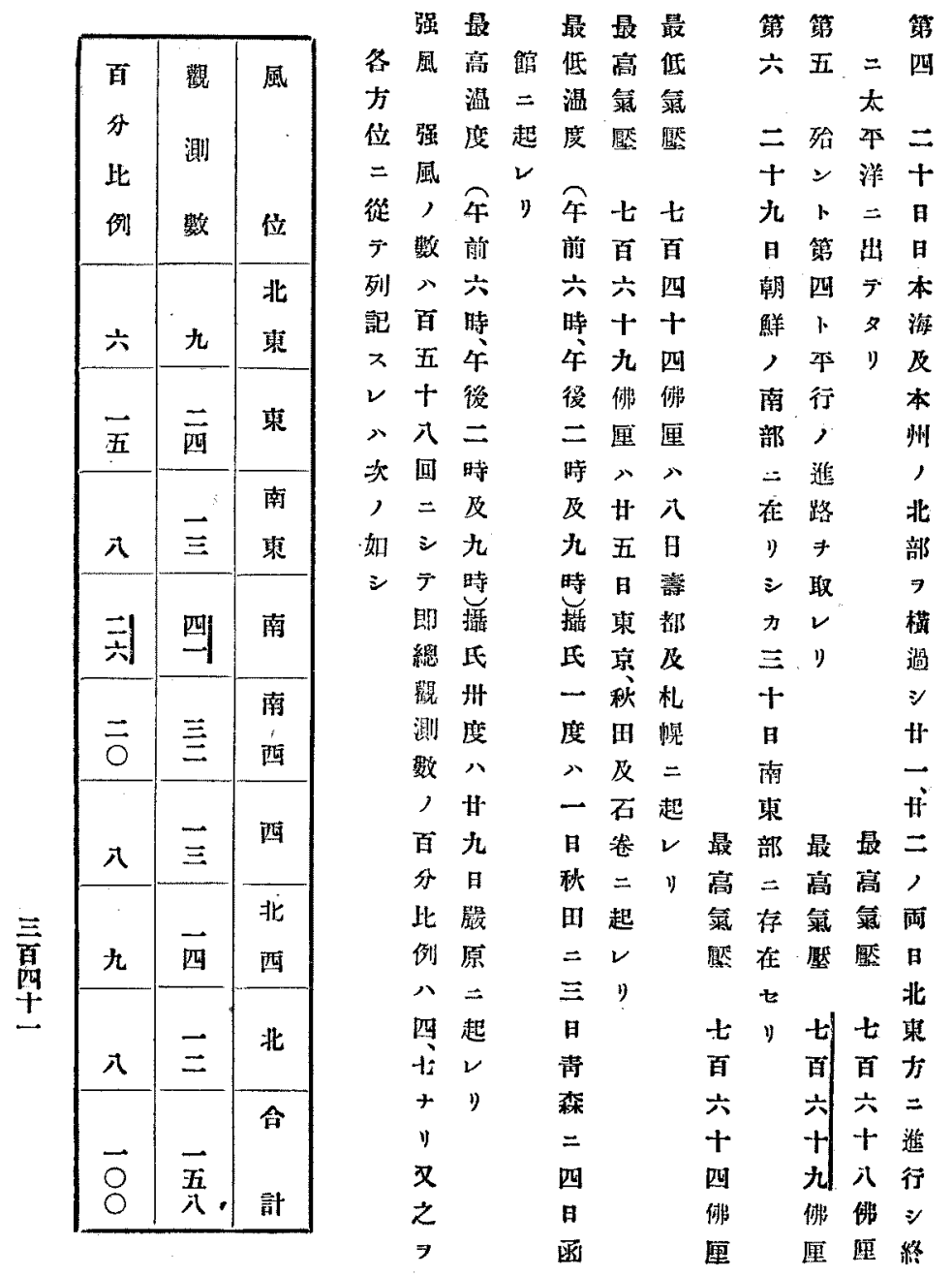




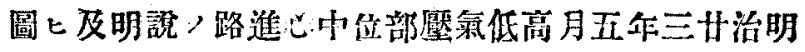

預大

强

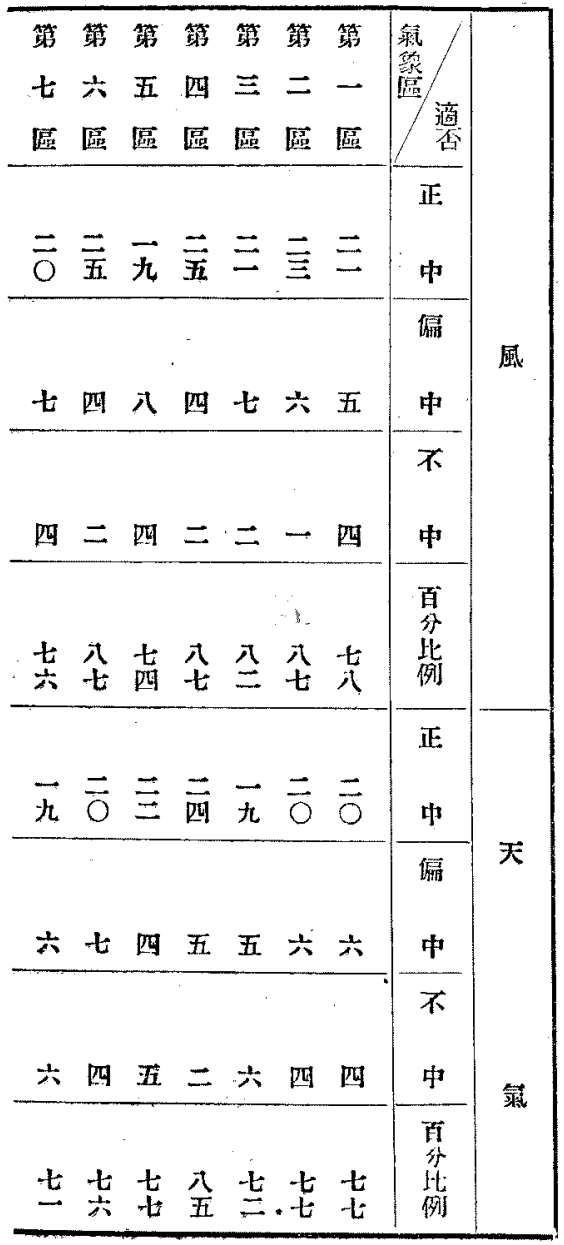

1)赤雨七三日風

七早 + ,

區全五五九广时

人氣策三日一及

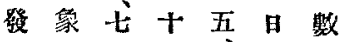

八區日入三九

三中三日十市二

$+-十 \equiv-\equiv$ 日

一區六三日 $\mathrm{日} \equiv$

回寻年三五 三

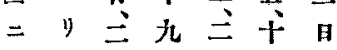

シ三十日十三四

厂區七一二日四

其一 日 $三$ 日

百發度十七十四

分主至三四亩

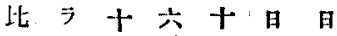

例 $2-三$ 四三四

八 $\Rightarrow$ 日十日十宍

次 $儿=-二$. 五 日

, 天大日 三日一

如氣雨九十三0

三隐降五十它

報 日六日

, $\quad$ 整

$\therefore \quad+\dot{a}$

三總六七日

备計日

回一六旭

pij $\rightarrow-\dot{\text { 日 }}$

區五三八公

$\exists$ 八十日十 


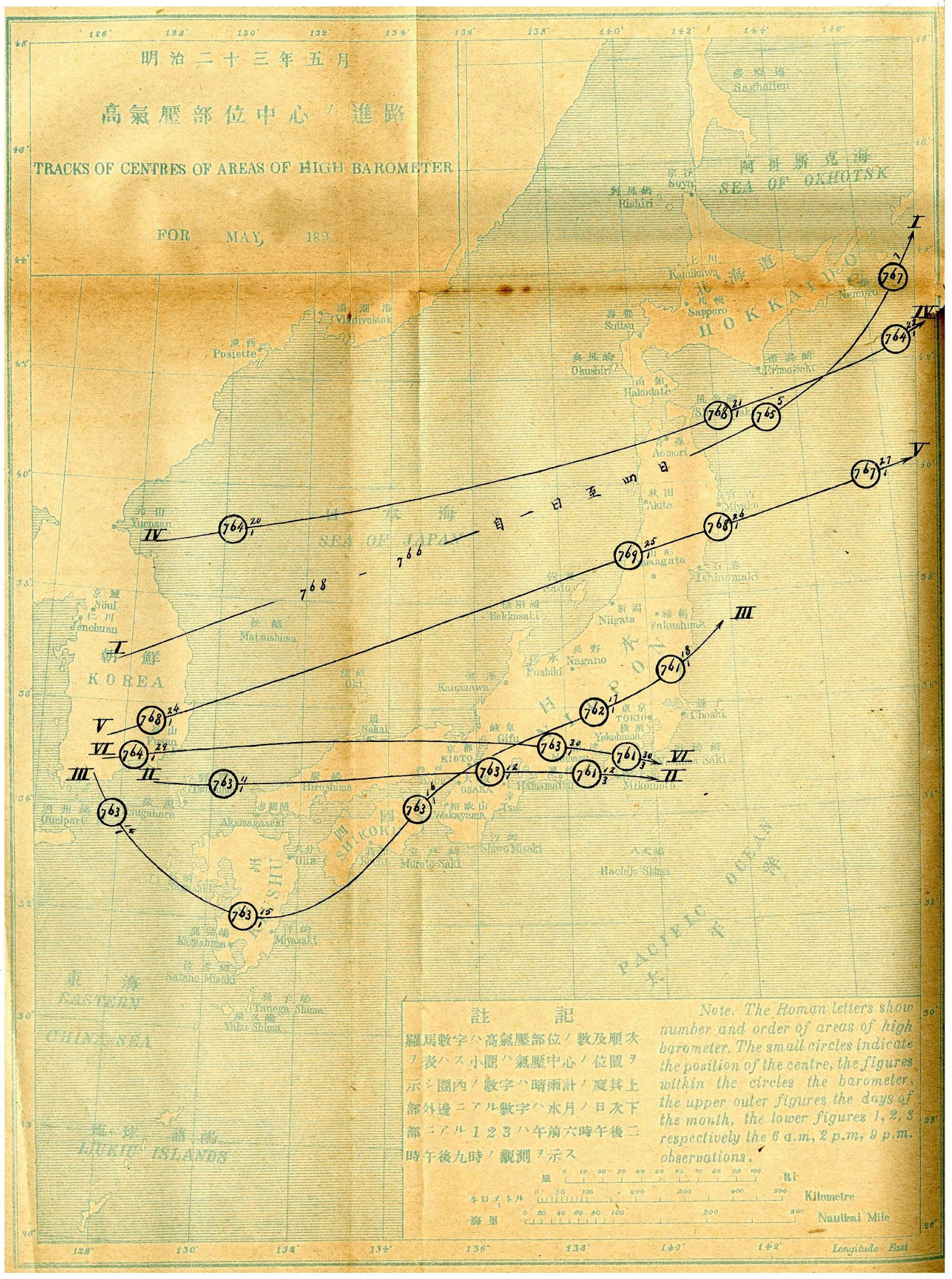




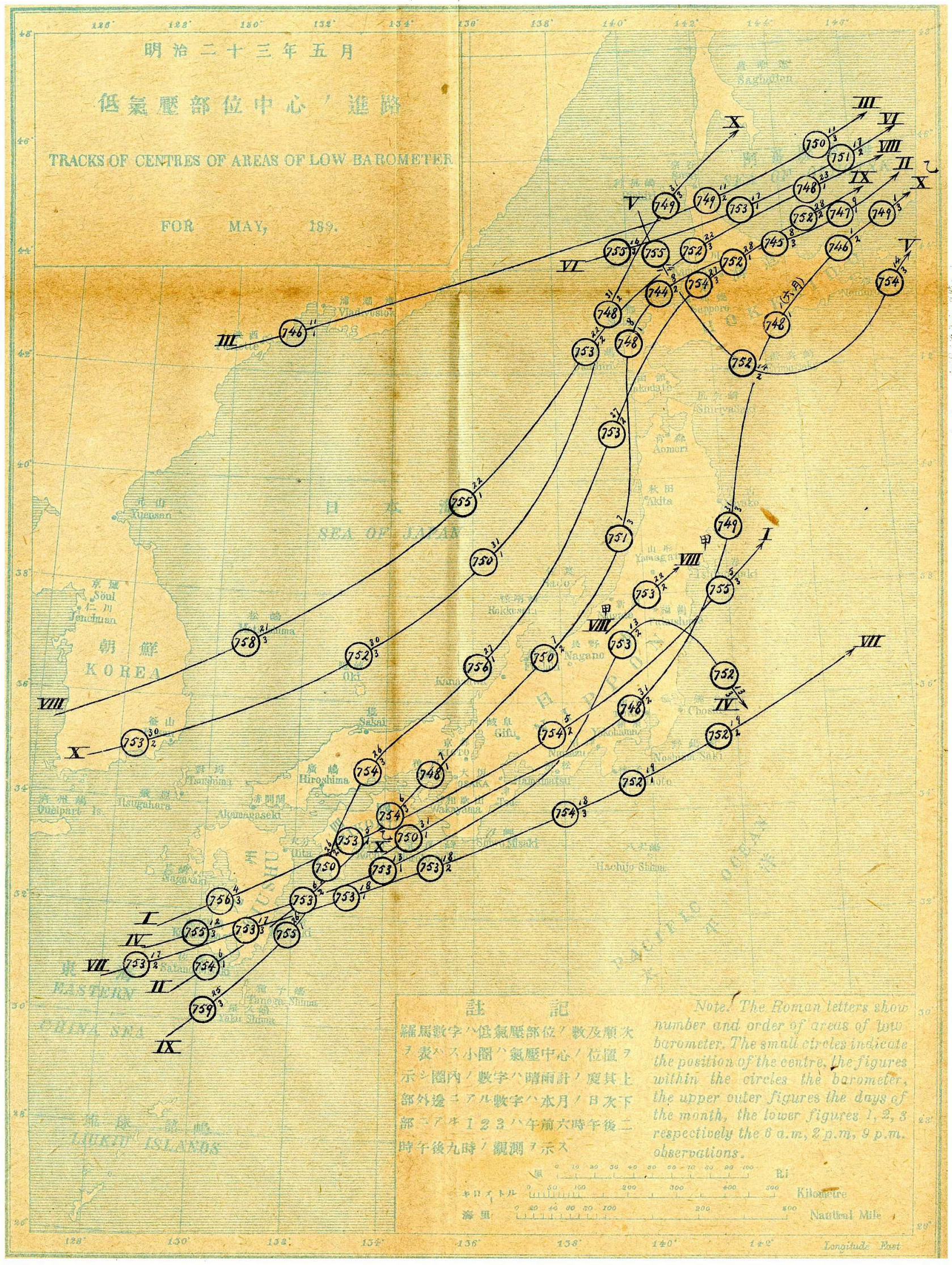




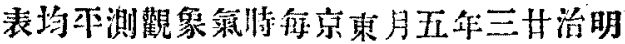

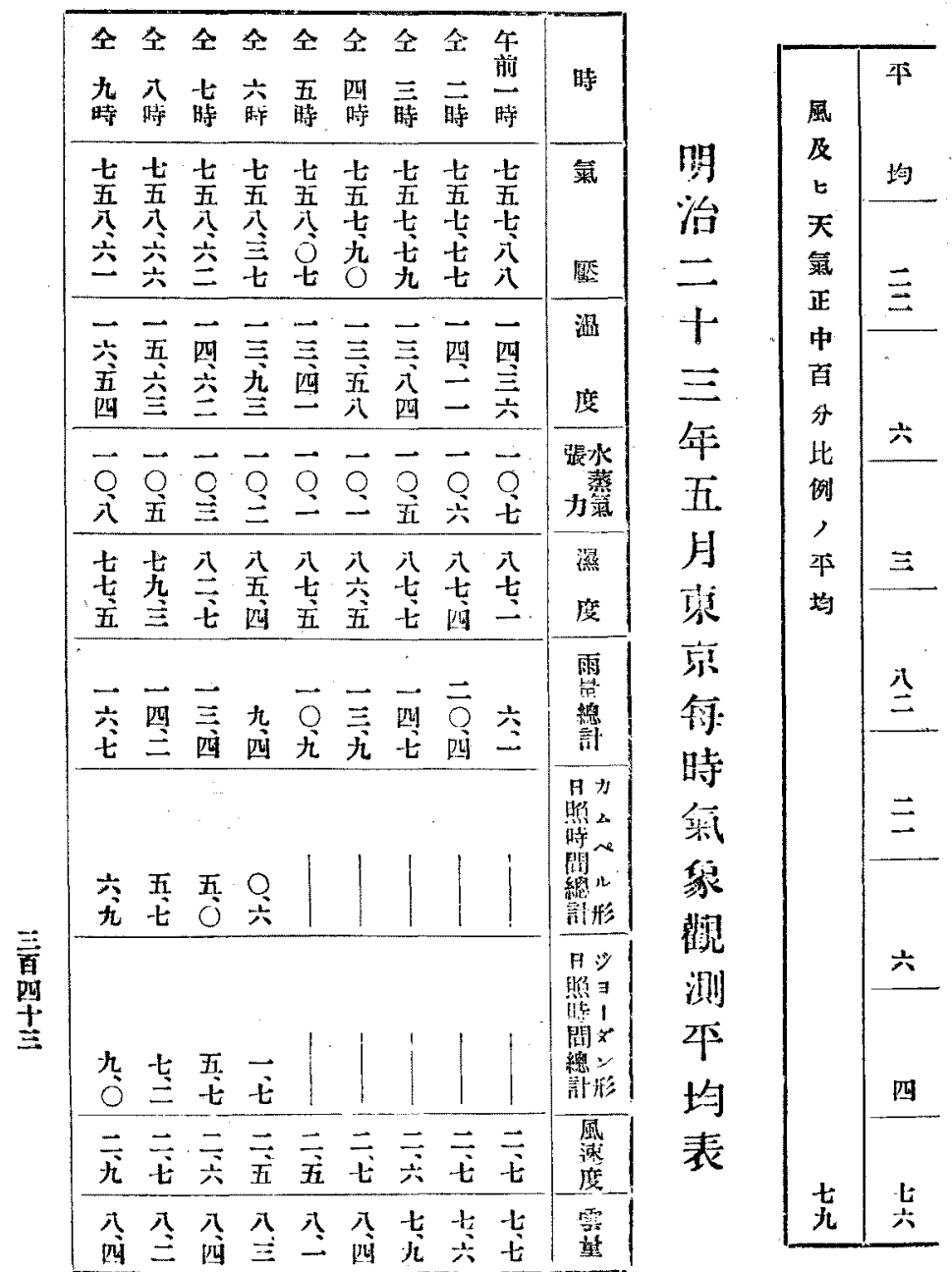

